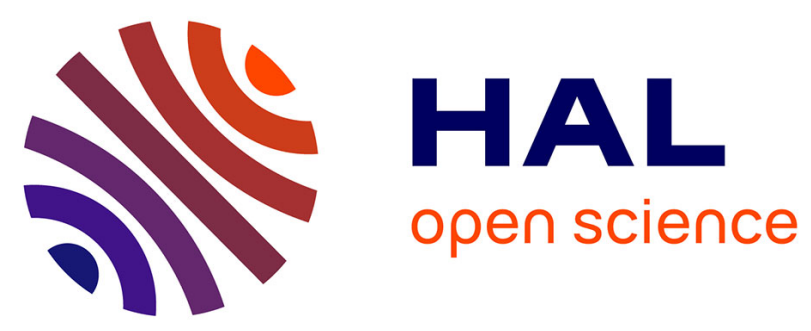

\title{
Soft mold NanoImprint Lithography: A versatile tool for sub-wavelength grating applications
}

\author{
Sylvain Pelloquin, Sylvain Augé, Ksenia Sharshavina, Jean-Baptiste Doucet, \\ Anatole Héliot, Henri Camon, Olivier Gauthier-Lafaye
}

\section{To cite this version:}

Sylvain Pelloquin, Sylvain Augé, Ksenia Sharshavina, Jean-Baptiste Doucet, Anatole Héliot, et al.. Soft mold NanoImprint Lithography: A versatile tool for sub-wavelength grating applications. 19th Symposium on Design, Test, Integration and Packaging of MEMS/MOEMS (DTIP 2017) , May 2017, Bordeaux, France. 5p., 10.1109/DTIP.2017.7984454 . hal-01670171

\section{HAL Id: hal-01670171 \\ https://hal.laas.fr/hal-01670171}

Submitted on 21 Dec 2017

HAL is a multi-disciplinary open access archive for the deposit and dissemination of scientific research documents, whether they are published or not. The documents may come from teaching and research institutions in France or abroad, or from public or private research centers.
L'archive ouverte pluridisciplinaire HAL, est destinée au dépôt et à la diffusion de documents scientifiques de niveau recherche, publiés ou non, émanant des établissements d'enseignement et de recherche français ou étrangers, des laboratoires publics ou privés. 


\title{
Soft mold NanoImprint Lithography: a versatile tool for sub-wavelength grating applications
}

\author{
S. Pelloquin, S. Augé, K. Sharshavina, J.-B. Doucet, A. Héliot, H. Camon, and O. Gauthier-Lafaye \\ LAAS-CNRS, Université de Toulouse, CNRS \\ Toulouse, FRANCE \\ sylvain.pelloquin@laas.fr
}

\begin{abstract}
Due to its independency to the substrate used, Soft mold NanoImprint Lithography (S-NIL) is a technique of great interest in particular for the fabrication of optical devices. We demonstrate a mature pathway for the realization of optical filters from the conception to the optical characterization. Those filters can be realized on large surfaces (up to 6" diameter wafers) with high conformity on various substrates. Quality of the transfer will be discussed throughout the process and optical performances compared to those obtained with classical techniques. In this paper we fabricated tunable spectral filters with a grating periodicity down to $260 \mathrm{~nm}$ and imprint surfaces up to 6". Physical conformity of the gratings will be discussed in terms of long-range stitching obtained on 6" Si hard mold, dimensional shrinkage during thermal NanoImprint on Zeonor ${ }^{\circledR}$ soft mold and conformity towards patterned hard mold throughout the process.
\end{abstract}

Keywords-NanoImprint Lithography; Soft Stamp; GMRF; CRIGF; Grating Filters

\section{INTRODUCTION}

Guided-Mode Resonant Filters (GMRFs) constitute a new family of ultra-selective and wavelength-tunable spectral filters [1] useful for applications from optical telecommunications to spectroscopy. Using only a few nanostructured layers, it allows complex optical filtering functions, hardly accessible to conventional multi-stack interference films filters [2], [3]. They are generally fabricated by stacking and structuring layers on a glass substrate to perform filtering, guiding and coupling/decoupling functions with a sub- $\lambda$ grating. The ultranarrow filtering relies on the perturbative Bragg coupling by a grating coupler of an incident plane wave and a guided-mode propagating inside the multi-layer stack. Their wavelength of resonance can be tuned by changing the angle of incidence of the plane wave. They can be designed to offer polarization independence and wide tuning range. The practical key issue with GMRFs is the lack of angular acceptance: ultra-narrow spectral width is only achievable with wide and perfectly collimated incident beams and large-area, homogeneous, GMRFs.

More recently was introduced the concept of cavity resonator integrated guided-mode filters (CRIGFs) [4] that offers spectral filtering width similar to that of GMRFs with smaller footprints working on tightly focussed beams [5]. Contrary to GMRFs, CRIGFs offer large angular acceptance and the filtered wavelength and spectral width are independent of the angle of incidence. These unusual properties have been harnessed to design small, wavelength-stabilized and particularly robust extended-cavity laser diodes where the CRIGF is used as a spectrally selective end mirror in a cat's eye cavity [6].

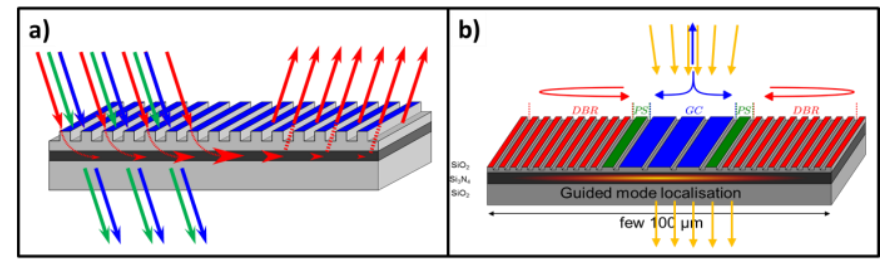

Fig. 1. Schematic view of a) standard GMRF configuration and b) CRIGF configuration. In both cases a guided mode is coupled/uncoupled with incident light by sub- $\lambda$ grating which results in a reflection filtering. In the GMRF case, filtering wavelength is strongly dependant on the incidence angle (best for plane wave). In the CRIGF case, a lateral cavity effect allows for smaller dimensions and better angular acceptance (best for focussed beams in normal incidence)

Those sub-micronic dimensions are easily accessible with standard microelectronic tools like stepper lithography but the complex optical response in the case of transparent substrates distorts automatic alignment systems of projection optics. On the other hand direct-writing structuration technique (e.g. electronic lithography) are time-consuming complicated by the use of insulating substrates and less reproducible for surfaces more than a few hundreds of square micrometers.

An interesting alternative lies in the use of Soft mold NanoImprint Lithography (S-NIL see Fig. 2) that allows to mechanically imprint a mold in a thermo-formable (or UVcurable) resin. This approach avoids contrast issues from optical technique and allows printing on large surfaces with a good conformity and resolution down to tenth of nanometers [7].

Thus, one can take advantage of the long experience on microelectronics standards to fabricate high-quality hard mold on $\mathrm{Si}$ (up to 6" in our case) nanostructured by a desired grating. Once this mold is fabricated, it can be transferred by thermal NIL (T-NIL) on a thermo-formable flexible sheet (Zeonor $\left.{ }^{\circledR}\right)$ that acts as an intermediary mold. On a second step, NanoImprint equipment is used to press the Zeonor ${ }^{\circledR}$ soft mold on the sample prepared with a home-made curable resin (NILUV135 [8]) while UV exposition is performed through the transparent Zeonor®. Our innovative home-made resist is 
inexpensive, easy to produce and provides flawless nanoimprints without bubbles unlike some industrial resins; it is used as a mask for etching in a PECVD step. The choice of the intermediary soft mold process lies in the fact that impact of an eventual dust is reduced compared to a hard-to-hard contact. Thus patterns can be reproduced at will on glass samples - either partially or totally.

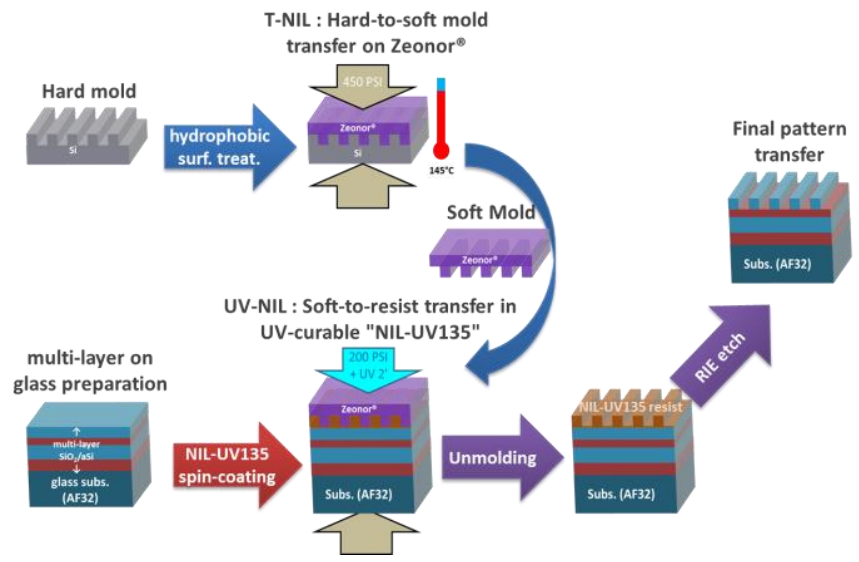

Fig. 2. Schematic representation of the S-NIL process flow for the structuration of multi-layers on glass.

\section{HARD MOLD FABRICATION AND SOFT MOLD STRUCTURATION BY THERMAL-NANOIMPRINT LITHOGRAPHY}

The main interest of the S-NIL lies in the fact that the desired patterns can be prepared independently on simple silicon wafers and are only limited by microelectronics standards. A single patterned hard mask can then be transferred at will on many samples regardless of the nature or size of the substrate. As a consequence we will describe in this part the preparation of two types of hard molds addressing two complementary issues: the fabrication of large surface seamless gratings and the realization of ultimate dimension complex gratings.

\section{A. Large surface GMRF preparation}

GMRF prepared in our team have relatively loose physical dimensions (pitch $880 \mathrm{~nm}$, grooves width 400-500 nm) accessible to stepper lithography technologies. With careful adjustments of the stepping parameters, we manage to precisely assemble the $18 \times 20 \mathrm{~mm}^{2}$ photo-repeated dyes to form one seamless $18700 \mathrm{~mm}^{2}$ grating (Fig. 3). Si wafers are prepared with a bi-layer resist spin-coat: first a $200 \mathrm{~nm}$ Bottom Anti-Reflective Coating (AZ Barli II) to ensure optimum exposure resolution in the superior layer constituted of a $1.2 \mu \mathrm{m}$ of AZ ECI-3012 photoresist. UV exposure $\left(110 \mathrm{~mJ} / \mathrm{cm}^{2}\right)$ is then performed on a Canon FPA-3000i4 stepper lithography tool equipped with a $5 x$ projection lens. An automatic tool (EVG120) is then used to perform a postexposure bake $\left(90 \mathrm{sec}\right.$ in proximity at $\left.110^{\circ} \mathrm{C}\right)$ and a spin-anddispense resist revelation with MF-CD26 developer. Revealed wafers are then etched in a Trikon Omega-201 ICP-RIE tool in two steps both using the photoresist as mask: the first one to remove the $200 \mathrm{~nm}$ BARC layer with a combination of $\mathrm{O}_{2} / \mathrm{CHF}_{3} / \mathrm{CF}_{4} / \mathrm{Ar}$ (5:1:1:1) and the second step to actually etch the Si layer with a mix of $\mathrm{C}_{4} \mathrm{~F}_{8} / \mathrm{SF}_{6} / \mathrm{O}_{2}(15: 10: 1)$. For the purpose of our devices, grooves depth of the hard mold must be at least $120 \mathrm{~nm}$ which is easily accessible by this process.

The 6" Si hard mold presented in Fig. 3 has been intensively characterized by Atomic Force Microscopy (right inset) to determine etching depth $(130 \pm 5 \mathrm{~nm}$ made in 17 measurements equally distributed over the whole surface). SEM image (left inset) allows us to qualify the verticality of etched trenches and determine the etching factor, EF (width of the trenches divided by the pitch) of $57 \pm 3 \%$ - i.e. the greatest observed EF variation is roughly $50 \mathrm{~nm}$. A tricky exercise was to find the location of the encounter between the four dyes combined to form an almost-seamless grating: in this image captured approximately at mid-radius on the lower-left side of the wafer, we can observe that the greatest misalignment is less than $100 \mathrm{~nm}$ (around $70 \mathrm{~nm}$ ).

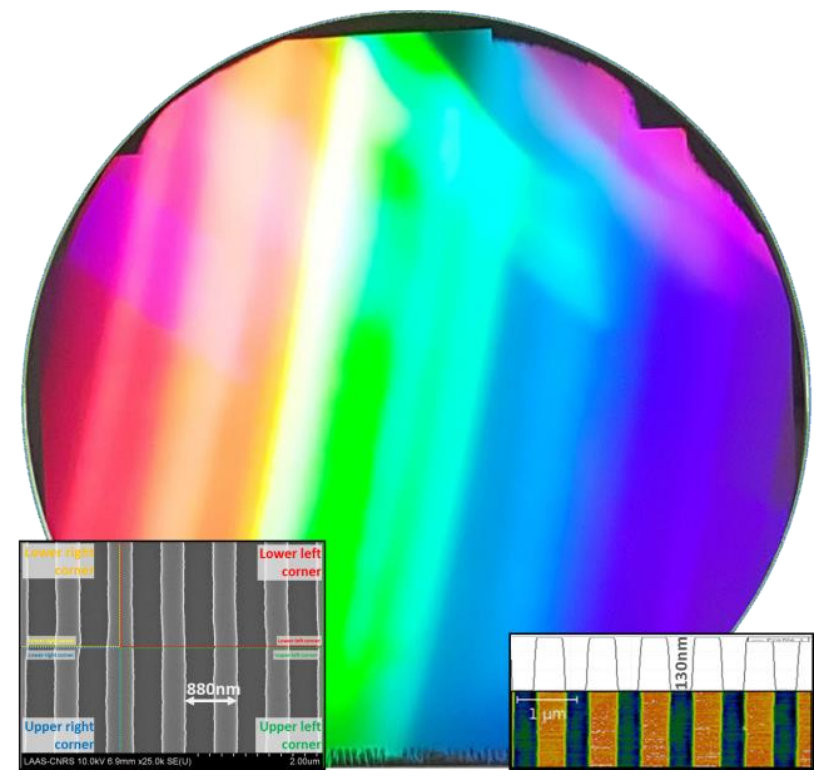

Fig. 3. Photography of a 6" $\mathrm{Si}$ hard mold grating filter constituted of $18 \times 20 \mathrm{~mm}^{2}$ dyes photorepeated 52 times. Left inset: SEM view showing the stitching between 4 dyes. Grating periodicity is $880 \mathrm{~nm}$ with an etching factor of $57 \pm 3 \%$; the visible uncoupling between grooves is roughly $70 \mathrm{~nm}$. Right inset: AFM measurements (log scale colors) of a typical grating presenting an etching depth of $130 \mathrm{~nm}$.

\section{B. CRIGF preparation}

Besides those large surface structuration issues stands another configuration that needs to be addressed in the resonant grating filter family: the Cavity Resonant Integrated Grating Filter (CRIGF) that basically consists in a central Grating Coupler (GC) surrounded by two Distributed Bragg Reflectors (DBRs) whose grating periodicities are bound to the GC one by a factor 0.5 (Fig. 4). The interest of such devices will be discussed in the fifth part of this paper but the technical challenge here lies in the realization and the reproducibility of small size $\left(5000-10000 \mu \mathrm{m}^{2}\right)$ and low-dimension gratings while periodicity of lateral DBRs is half of those of the central GC. Pitches and etching factors here are not accessible to our projection lithography stepper but can be obtained by e-beam lithography.

For CRIGF hard molds preparation, $140 \mathrm{~nm}$ PMMA ( $37 \mathrm{~g} / \mathrm{L})$ is spin-coated on $2 \times 2.5 \mathrm{~mm}^{2} \mathrm{Si}$ substrates, heated at 
$170^{\circ} \mathrm{C}$ for $5 \mathrm{~min}$ and direct writing is performed in a Raith-150 e-beam lithography equipment $\left(222 \mu \mathrm{C} / \mathrm{cm}^{2}, 20 \mathrm{kV}\right)$. Resist is then revealed with MIBK IPA-diluted solution (1:3) and the substrate is etched by ICP-RIE in the ICP3 tool previously described in $\mathrm{C}_{4} \mathrm{~F}_{8} / \mathrm{SF}_{6} / \mathrm{O}_{2}$ atmosphere.

As for the large scale GMRF, the CRIGF hard mold fabrication is well controlled with GC and DBR pitches of respectively 520 and $260 \mathrm{~nm}$ and etching factors of 40 and $50 \%$. AFM measurement showed grooves depth of $115 \mathrm{~nm}$ on GC and DBR parts.

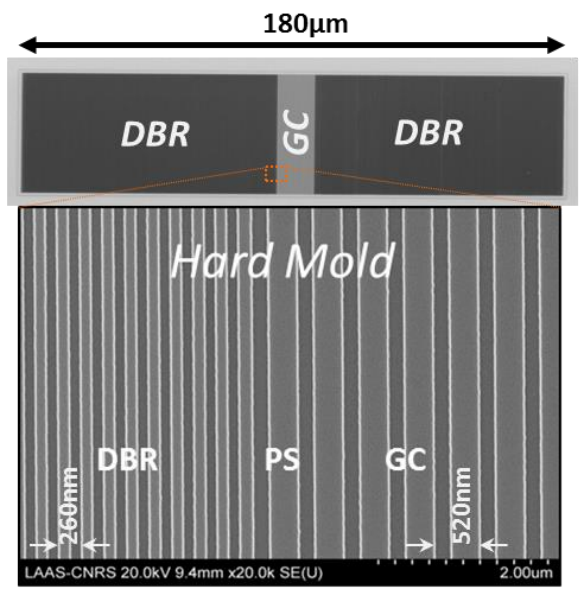

Fig. 4. Microscopy view of the Si hard mold of a CRIGF device (upper part) and SEM view (lower part) of the transition between the central Gradient Coupler (GC) and the left Distributed Bragg Reflector (DBR) separated by a Phase Shift (PS).

\section{T-NIL hard mold transfer and conformity}

The first step of the so-called Soft mold NIL (S-NIL) consists of transferring the imprint of the hard mold on an intermediary thermo-formable foil. Thermal NIL is performed on a Nanonex NX-2500 equipment: hard mold surfaces are beforehand prepared with an hydrophobic FDTS treatment to facilitate unmolding. The NIL tool consists of an pneumatic press that can accept samples up to 6" wafers with a doublesided flexible chamber to ensure a perfect repartition of the applied pressure. Six IR bulbs are present in the lower part of the chamber and UV light can be conducted to upper part through the flexible membrane. Hard mold is positioned on the lower membrane and a virgin Zeonor ${ }^{\circledR}$ sheet is applied on the upper membrane. During the T-NIL a rough vacuum is made to avoid bubbles formation between the sheet and the mold, pressure and temperature are applied in two steps: pre-imprint step at $120 \mathrm{psi}$ and $120^{\circ} \mathrm{C}$ for $1 \mathrm{~min}$ then $450 \mathrm{psi}$ and $145^{\circ} \mathrm{C}$ for 3 min. Soft molds obtained are then manually separated and are ready to use for the next step. Those molds are especially difficult to characterize but AFM and SEM measurements (Fig. 5) showed perfect conformity of the gratings obtained (obviously as a negative imprint) should it be for the GMRF or the CRIGF configuration. The only variation observed is due to the plastic retraction of the Zeonor $\AA$ as it cools back to room temperature. All dimensions are reduced by $0.5 \%$.

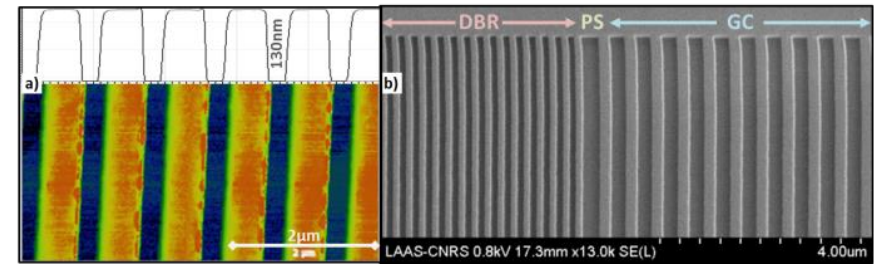

Fig. 5. Characterizations of soft molds obtained by T-NIL on Zeonor ${ }^{\circledR}$ sheets: a) AFM measurements (log scale colors) of GMRF grating corresponding the inverse of the hard mold; periodicity is reduced by $0.5 \%$ and grooves depth is conserved $(130 \mathrm{~nm})$; b) SEM image of transition zone between DBR and GC of a CRIGF soft mold

Considering our extensive experience in terms of grating imprints, we determined that the maximal aspect ratio reachable with this technique is $1.5: 1$ and maximal transferable grooves depth is $180 \mathrm{~nm}$.

\section{UV-NANOIMPRINT LITHOGRAPHY : SOFT MOLD TRANSFER IN NIL-UV135 RESIST AND RIE TRANSFER ON SAMPLES}

On another hand, samples to be structured have been prepared on glass substrates (4', Schott AF32; thickness $500 \mu \mathrm{m})$ by deposition of alternative optical layers $\left(\mathrm{SiO}_{2} / \mathrm{a}-\mathrm{Si}\right.$ in the case of standard GMRFs and $\mathrm{SiO}_{2} / \mathrm{Si}_{3} \mathrm{~N}_{4}$ for CRIGFs; typical thicknesses between 30 and $100 \mathrm{~nm}$ ). Photo-sensitive resist is then spin-coated on the sample to obtain a coating around $120 \mathrm{~nm}$. Commercial photoresists revealed inappropriate towards Zeonor ${ }^{\circledR}$ contact and $\mathrm{SiO}_{2}$ wetting and we finally developed our home-made photo-resist: NIL-UV135 - that will be described in a coming article - is based on a solvent-free methacrylate monomers solution that allows thicknesses between 90 and $270 \mathrm{~nm}$. After coating and baking $\left(2 \mathrm{~min}\right.$ at $60^{\circ} \mathrm{C}$ ), sample is installed in the NIL chamber in front of the desired soft mold. UV-NIL step consists in 3 min UV exposure under 200 psi pressure at room temperature through the transparent Zeonor ${ }^{\circledR}$ mold.

Soft mold is then separated from the reticulated resist and we can observe the transfer of the patterns in Fig. 6-a. A scratch has been made on qualification samples to access to the substrate and estimate the remaining resist at the bottom of the grooves (further called "floor resist"): thickness of this layer is generally around $50 \mathrm{~nm}$. This floor resist has first to be removed to properly etch the underlying $\mathrm{SiO}_{2}$ layer. In order to do so a simple ICP-RIE step is performed in a Sentech EtchLab-200 in $\mathrm{O}_{2}$ atmosphere whose result can be seen in Fig. $6 b)$.

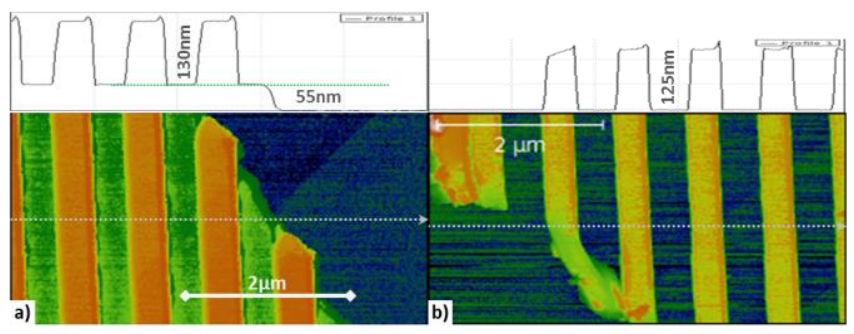

Fig. 6. AFM measurement (log color scale) on GMRF patterns imprinted on qualification samples volontarily scratched to quantify resist floor a) after UVNIL in the resist (the lowest level corresponding to the substrate) b) after resist floor ICP-RIE revealing the substrate. 


\section{FINAL STRUCTURATION RESULTS}

\section{A. Conformity qualification}

Finally the patterned NIL-UV135 resist is used as an etching mask to transfer the desired gratings in the $\mathrm{SiO}_{2}$ layer. The same EtchLab200 chamber is used to carry out an ICP-RIE in $\mathrm{CHF}_{3}$ atmosphere with a selectivity towards $\mathrm{SiO}_{2}$ of $1: 1$. Fig. 7 shows a picture of a $60 \mathrm{~nm}$-deep GMRF pattern transferred on a full 4" $\mathrm{SiO}_{2} / \mathrm{a}-\mathrm{Si} / \mathrm{SiO}_{2} / \mathrm{a}-\mathrm{Si} /$ glass sample (respective thicknesses $61,49,120,74 \mathrm{~nm}$ on $500 \mu \mathrm{m}$ thick glass); the inset presents one of the AFM measurements typically performed on such samples. Depth variations are well within AFM limitations (a few nanometers variation for a measured depth of $60 \pm 2 \mathrm{~nm}$ on 13 points distributed over the surface).

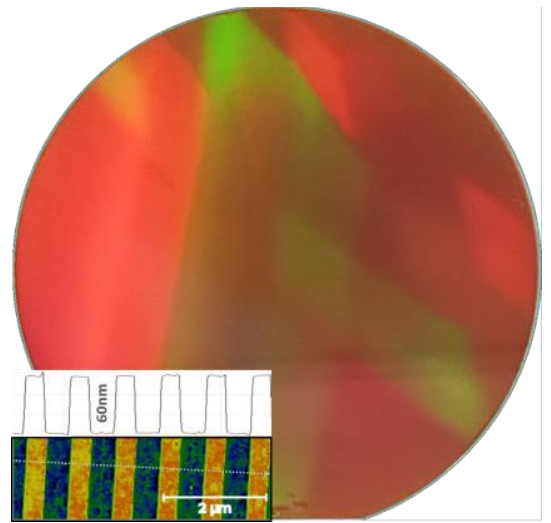

Fig. 7. Photography of a 4 " $\mathrm{SiO}_{2} / \mathrm{a}-\mathrm{Si}$ multilayer on glass substrate whose last layer $\left(\mathrm{SiO}_{2}\right)$ has been structured with GMRF pattern by S-NIL process. Red and green shapes come from diffraction of visible light at the chosen angle of capture. Inset shows one of the Atomic Force Micrographs (log scale colors) done to estimate the conformity of the transfer.

Similarly good results have been obtained on CRIGF configurations as can be seen on Fig. 8. CRIGF patterns are totally transferred in the $\mathrm{SiO}_{2}$ layer (Fig. 8-a) and the etched depth ( $85 \mathrm{~nm}$ measured by AFM) is the same whether on the DBR (Fig 8-b) or on the GC (Fig. 8-c) part. One can notice that the $\mathrm{EF}$ is the identical to the corresponding on the hard mold so the lateral etching must be very weak (not measurable).

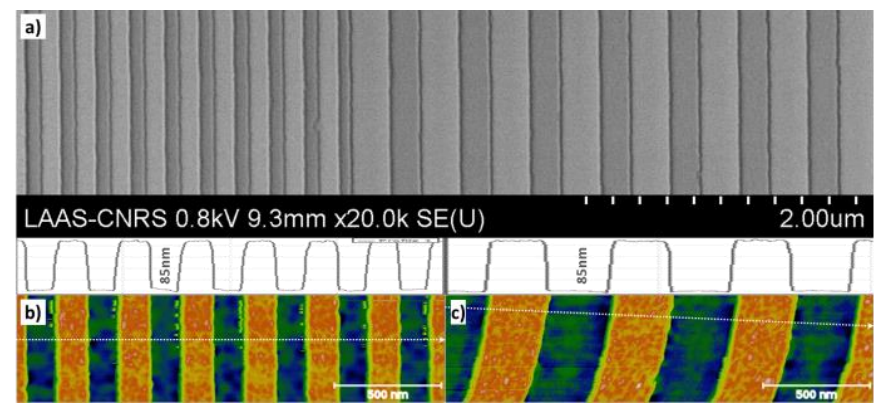

Fig. 8. Characterizations of final grattings etched in $\mathrm{SiO}_{2}$ layer patterned by S-NIL technique from a CRIGF hard mold: a) SEM image of transition zone between DBR and GC of a CRIGF ; b \& c) corresponding AFM measurements (log scale colors) on the DBR part (b) and on the GC part (c); grooves depth in both case is $85 \mathrm{~nm}$.

\section{B. Defectivity issues and limitations}

Results shown here are obviously our best performances but numerous trials and errors allowed us to encounter typical defects presented in Fig. 9. One must notice that one of the best advantages of the S-NIL techniques lies in the re-usability of the once-and-for-all realized hard mold, the low cost of consumables implied and the ability to re-process a faulty sample.

Fig. 9-a shows the impact of a 100- $\mu$ m-diameter dust that impacted the imprint on a 2-mm-diameter disc around it. Here we can see the advantage of the soft-to-hard contact chosen in the S-NIL process since such dust often lead to much problematic impact areas with hard-to-hard contact (and even breakage of one or both surfaces in contact). Fig. 9-b presents a microscopic view of a so-called "marbling" usually visible to the naked eye after imprint in NIL-UV135 resist and resulting - as can be seen in the inset - from lacking parts in the lines. From primary results, this defects are believed to come from the first NIL step (soft vs. hard mold) where localized stress and/or temperature variations could lead to faulty grooves that are furthermore transferred in the resist.

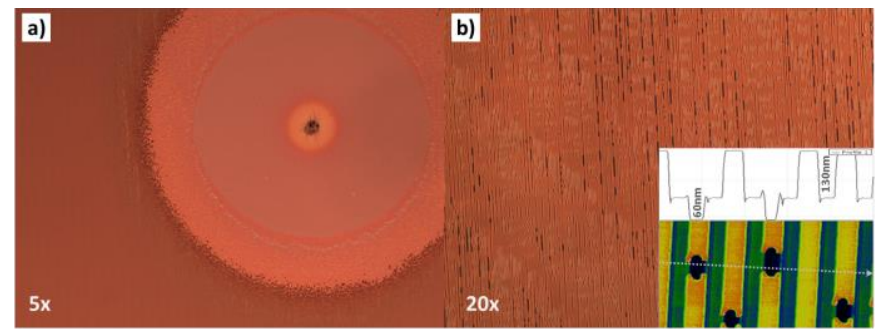

Fig. 9. Microscopic views of typical defects obtained with S-NIL: a) a 100 $\mu \mathrm{m}$ diameter dust trapped between the soft mold and the resist leads to a relatively circumscribed "non imprinted" area; b) "marbling" zones are sometimes visible that are attributed to faulty zones in the soft mold.

Nonetheless this study on large surface transfer has not be performed in the ultra-high standards of microelectronics and we believe that if we are able to obtain almost perfect 4" samples with our known contamination sources, the same process realized in cleaner conditions would lead to perfect samples in the actual microelectronic standards.

\section{OPTICAL PERFORMANCES}

In this part, optical performances of the devices obtained by this S-NIL process will be compared to previous results obtained by classical techniques (direct writing or photolithography on sample).

For the GMRF configuration, we analyzed here the optical response of a $2 \times 2 \mathrm{~cm}^{2}$ sample on our optical bench composed of a polarized tunable laser $(1500-1630 \mathrm{~nm} ; 3 \mathrm{~mW})$ pointed on a motorized sample carrier and two InGaAs detectors to record transmitted and reflected light. Gratings are aligned with the polarization of the incident beam (itself perpendicular to the incidence plane) so that the eigenmode of the structure can be excited by one order of diffraction of the in-plane wave vector. As this resonant condition occurs, the transmission characteristic -designed to be anti-reflective in the wavelengths range of interest - exhibits a sharp reflection peak whose spectral position can be tuned by changing the angle of incidence.

Fig. 10-a shows a colorimetric map of measured transmission for incidence angle from 0 to $10^{\circ}$ and incident 
wavelengths from 1500 to $1630 \mathrm{~nm}$ : tunability of the filter is $12.4 \mathrm{~nm} /{ }^{\circ}$ in good agreement with our predictions. Fig. 10-b presents corresponding transmission and reflection spectra (respectively plain and dashed spectra) obtained at different incidence angles $\left(3.4,4.2\right.$ and $\left.5^{\circ}\right)$. Very good performances are observed: high reflection intensity (median value at $89.5 \%$ between 3 and $10^{\circ}$ ), high transmission outside of the resonance peak $(95.0 \pm 0.5 \%)$ and spectral width around $2 \pm 0.2 \mathrm{~nm}$.
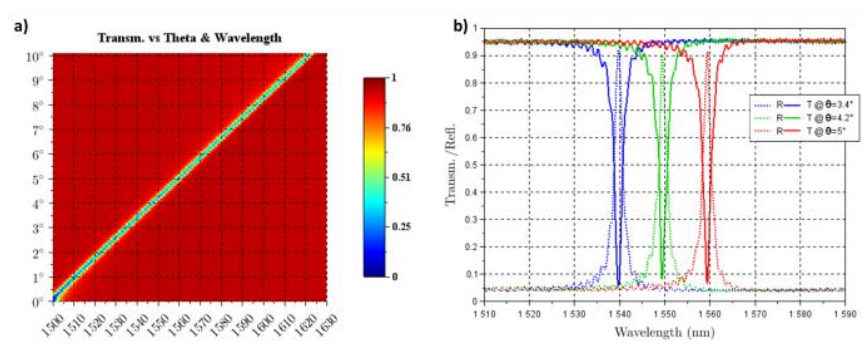

Fig. 10. Optical characteristic of GMRF filter (periodicity $875 \mathrm{~nm}$, EF 57\%, etch depth $60 \mathrm{~nm}$ ) prepared by S-NIL technique: a) Colorimetric map of transmited light vs. incident wavelength at incidence angles from 0 to $10^{\circ}$ (step $0.1^{\circ}$ ); b) Transmitted and reflected spectra for 3 chosen angles (around $1540,1550,1560 \mathrm{~nm})$.

Concerning CRIGF configuration, samples fabricated with our S-NIL technique have been characterized in normal incidence with a fiber-coupled swept laser source $(820-870 \mathrm{~nm}$ collimated with a 50-mm focal-length lens). Reflection/Transmission spectra of the structures shown in the previous part (Fig. 8) are presented in Fig. 11: Minimum transmission and maximum reflection at resonance $\left(\lambda_{\text {res }}=\right.$ $843.2 \mathrm{~nm}$ ) reach respectively $47 \%$ and $45 \%$ and FWHM of those peaks are around $0.4 \mathrm{~nm}$. These results are fully comparable with those obtained with classical techniques [4], [5].

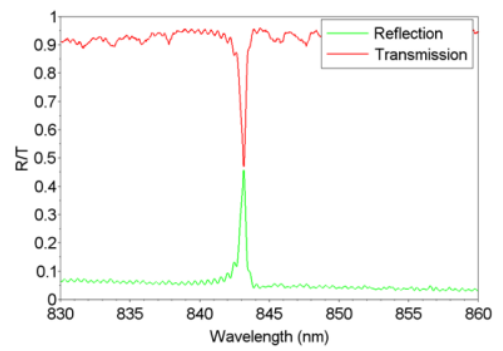

Fig. 11. Optical characteristics of a $\mathrm{SiO}_{2} / \mathrm{Si}_{3} \mathrm{~N}_{4} /$ glass CRIGF filter (GC period $520 \mathrm{~nm}$; EF 40\%; etching depth $85 \mathrm{~nm}$; AR backside): Transmission (red) and reflection (green) in normal incidence.

\section{CONCLUSIONS AND PERSPECTIVES}

NanoImprint Lithography is still a young technique that nonetheless begins to be implemented in microelectronics manufacture [9]. In this paper we exposed how the particular Soft Mold NIL can address peculiar integration issues for structuring material on transparent and/or insulating substrates. Also the patterns to be transferred can be prepared on simple $\mathrm{Si}$ substrate using all the background of microelectronics technologies and compatible with VLSI. Once a hard mold is fabricated, it can be used at will to prepare intermediary soft molds by a T-NIL step. Those soft molds can then be imprinted in a UV-curable resist (e.g. our home-made "NIL-UV135") that serves as a mask for etching step. Some limitations lie in the patterns depth (180 $\mathrm{nm}$ in our study) or the aspect ratio (1.5:1) due to the ability to separate the soft mold from the resist after UV-NIL.

Large surface GMRF filter hard molds have been fabricated by standard stepper lithography technique on 6" Si wafers whose patterns have been transferred by S-NIL on a complete 4" $\mathrm{SiO}_{2} / \mathrm{a}-\mathrm{Si} / \mathrm{SiO}_{2} / \mathrm{a}-\mathrm{Si} /$ glass. Reproduced gratings are consistent with the original hard mold and GMRF filters present good reflection performance (up to $90 \%$ with out-ofresonance at $5 \%)$ and spectral tunability $\left(12.4 \mathrm{~nm} /{ }^{\circ}\right)$.

CRIGF configuration have also been tested: these ones are designed to have a small footprint, better angular acceptance in normal incidence but the challenge here is to reproduce in the same process two different grating periodicities, one being half of the other. As the patterned surface was much smaller we used e-beam lithography to prepare the hard mold and successfully transferred the gratings on $2 \times 2.5 \mathrm{~cm}^{2}$ $\mathrm{SiO}_{2} / \mathrm{Si}_{3} \mathrm{~N}_{4} /$ glass samples. As for GMRFs, etched patterns were true to their hard molds counterparts and showed optical characteristics comparable with similar devices fabricated by classical e-beam lithography.

\section{ACKNOWLEDGMENT}

Authors acknowledge financial support from STAE under framework of the ATRIUM project. This work was partly supported by the french RENATECH network through LAASCNRS micro and nanotechnologies platform.

\section{REFERENCES}

[1] R. Magnusson and S. S. Wang, "New principle for optical filters," Appl. Phys. Lett., vol. 61, no. 9, pp. 1022-1024, Aug. 1992.

[2] A. Sharon, D. Rosenblatt, and A. A. Friesem, "Narrow spectral bandwidths with grating waveguide structures," Appl. Phys. Lett., vol. 69 , no. 27 , p. $4154,1996$.

[3] A. Monmayrant et al., "Experimental demonstration of 1D crossed gratings for polarization-independent high-Q filtering," Opt. Lett., vol. 39, no. 20, pp. 6038-6041, Oct. 2014.

[4] K. Kintaka, T. Majima, J. Inoue, K. Hatanaka, J. Nishii, and S. Ura, "Cavity-resonator-integrated guided-mode resonance filter for aperture miniaturization," Opt. Express, vol. 20, no. 2, pp. 1444-1449, Jan. 2012.

[5] X. Buet, E. Daran, D. Belharet, F. Lozes-Dupuy, A. Monmayrant, and O. Gauthier-Lafaye, "High angular tolerance and reflectivity with narrow bandwidth cavity-resonator-integrated guided-mode resonance filter," Opt. Express, vol. 20, no. 8, pp. 9322-9327, Apr. 2012.

[6] O. Gauthier-Lafaye et al., "Wavelength-stabilised external-cavity laser diode using cavity resonator integrated guided mode filter," Electron. Lett., vol. 48, no. 25, pp. 1619-1621, Dec. 2012.

[7] S. Y. Chou and P. R. Krauss, "Imprint lithography with sub-10 nm feature size and high throughput," Microelectron. Eng., vol. 35, no. 1, pp. 237-240, Feb. 1997.

[8] F. Doucet, J.-B. et al., "Transfert de nanostructures dans la silce par nanoimpression avec résines 'maison,"” presented at the Journées Nano, Micro et Optoélectronique, Les Issambres, France, May-2016.

[9] T. Singh, S. V. Sreenivasan, J. Choi, P. Schumaker, and F. Xu, "Status of UV Imprint Lithography for Nanoscale Manufacturing," in Reference Module in Materials Science and Materials Engineering, Elsevier, 2017. 